\author{
Ю.М. Резник
}

\title{
Я И ДРУГОЙ В КОНТЕКСТЕ МЕЖРЕГИОНАЛЬНОГО ВЗАИМОДЕЙСТВИЯ
}

\begin{abstract}
Аннотация. Предметом исследования в данной статье выступает региональные связи Я и Другого. "Я» и "Другой» (или бытие-с-другим) рассматриваются автором как "ядро» персональной реальности или персональное выражение межрегионального культурного и солидарного взаимодействия. Под регионом понимается отграниченное пространство персональной реальности одного или нескольких субъектов, отличающихся духовным единством, солидарностью или внешним сходством культурных стилей субъектов и стандартов их жизни. Автор показывает, что Я и Другой образуют сложную комбинацию разных регионов: внешних или внутренних, передних и ближних, дальних или ближних. Он описывает об-разы Других, которые вступают во взаимодействие с Я человека (Свой, Чужой, Иной, Враг) и тем самым модифицируют его самость. Дистанция между Я и Другим зависит от степени участия/неучастия в событиях друг друга. Другость выражает способность человека быть другим, оставаясь при этом самим собой.

Автор опирается на методологию френоменологии, ориентированную на раскрытие смыслов человеческого бытия и его основных методов - редукции, конструирования и деконструкции. При помощи этих методов он последовательно создает картину внутри- и межрегионального взаимодействия Я и Другого.

Новизна исследования состоит в определении регионов со-бытия Я и Другого, рассматриваемых в их единстве и различиях. Новым является подход автора к определению основных регионов со-бытия людей. $B \mathrm{cma-}$ тье впервые рассматриваются две формы или модели другости, которые раскрывают грани бытия Я и Другого: бытие с Другим я-субъектом и бытие с Другим я-объектом.

Ключевые слова: феноменология, феноменологический метод, редукция, конструкция, деконструкция, человек, со-бытие, регион, Я, Другой.
\end{abstract}

\section{От сущего к бытию: определение способов со-бытия Я и Другого}

O методе. О бытии человека с другими написано и сказано много. Но главное отличие данного исследования заключается в обнаружении адекватного метода его философского познания. Вслед за М. Хайдеггером я выбираю в качестве методологической основы методы феноменологии ${ }^{1}$. Именно ей дано найти ответ на вопрос о смысле бытия вообще, а не просто ограничиться суждениями о сущем (онтический уровень). Суть феноменологии в философии состоит в понимании бытия сущего, расшифровке его смыслов.

Феноменологический подход в интерпретации Хайдеггера базируется на различении бытия и сущего, которое определяется как онтологиче-

1 См.: Хайдеггер М. Основные проблемы феноменологии / Пер. с нем. А.Г. Чернякова. СПб.: Высшая религиозно-философская школа, 2001. 446 с. ски-трансцендентальное в отличие от онтического измерения (многообразия сущего). Он включает в феноменологию три компонента (метода): феноменологическую редукцию («возведение сущего к бытию», способу быть); феноменологическую конструкцию («набрасывание данного наперед сущего в направлении бытия и его структур»); деструкцию («демонтаж предания», возвращение к истокам).

В первую очередь феноменология имеет дело с представлением определенных видов сущего (феноменов персональной реальности человека) как разных способов бытия (например, «вот-бытие» и «там-бытие», «что-бытие» и «кто-бытие», «самобытие» и «инобытие», «бытие-для-себя» и «бытиес-другими» и пр.). С этого начинается процедура феноменологической редукции. Затем осуществляется конструирование (сборка и разборка) персональной реальности при помощи регионов.

Различение есть первый шаг в редукции (сведении) персональной реальности человека к его бытию. Наряду с «что-бытием» Хайдеггера я различаю 
«кто-бытие», которое подлежит феноменологическому описанию. Как известно, что-бытие есть бытие конкретного сущего (чтойность). «Чтойность, устанавливаемая в дефиниции, есть то самое, что придает каждой вещи свойственную ей определенность и надежную отличимость от иного, то, что образует ее очерченность, ее облик» ${ }^{2}$. Другими словами, это качественная определенность конкретного сущего (вещи или явления), объектное бытие, которое преимущественно изучают естественные и социальные науки. А кто-бытие находит своё воплощение в бытии человека как особого сущего, способного сознательно порождать другое сущее, используя материал мира, и ставить вопрос о смысле собственного существования (ктойность). Ктойностью занимаются гуманитарные науки и философия.

Субъектное бытие человека (ктойность) определяется двумя векторами развития: экзистенцией, т.е. бытием для того, кто существует как самость (самобытие), отличная от других самостей, и трансценденцией (инобытием), которая характеризует бытиеза-пределами. Трансцендентным по отношению к человеку выступает мир как совокупное и всеобъемлющее бытие («бытие-в-мире»), устанавливающее горизонт его познания и границу возможностей. «Мы стремимся, - писал К. Ясперс, - выйти за пределы всякого горизонта, который все-таки замыкает нас и не позволяет нам взглянуть шире» ${ }^{3}$. Экзистенция выражает решимость к подлинному бытию, «очеловеченному» человеком, а трансценденция - стремление вырваться на свободу, преодолеть земные оковы существования, стать частью мира, обладающей всем его могуществом и силой.

Философия (и непосредственно - философская антропология) есть пограничное знание, объединяющее трансцендентные и экзистенциальные начала человеческого бытия. Она склонна искать всеобщее не только в трансцендентном аспекте бытия, но и выводить его из истоков экзистенции. «Вместе с этим различением бытия и сущего и тематическим выделением бытия мы выходим за пределы области сущего. Мы преодолеваем, мы трансцендируем ее... Мы преодолеваем, превосходим сущее, чтобы прийти к бытию» ${ }^{4}$. Между транс-

\footnotetext{
2 См.: там же.

3 Ясперс К. Разум и экзистенция / Пер. с фр. В.И. Колядко. М.: Канон + РООИ «Реабилитация», 2014. С. 183-184.

4 Хайдеггер М. Основные проблемы феноменологии / Пер. с нем. А.Г. Чернякова. СПб.: Высшая религиозно-философская школа, 2001. С. 20-21.
}

ценденцией и экзистенцией лежит сфера бытия Другого, с которым вступает во взаимодействие наше «Я». Их связывает друг с другом персональная реальность.

Проблема «Я - Другой» в структуре бытия. Проблема «Я - Другой» находится в центре внимания современной философии. На первый взгляд другой не является мной и у него есть собственное «Я», не принадлежащее мне. Но я могу быть Другим и в Другом, если изменю свои установки. Путь человека к себе, как показывает Сартр, лежит через Другого. Я как «Я» (эго, сущее-для-меня) завишу в своём бытии от Другого. Иными словами, реальность Другого делает мою жизнь полной, хотя мы находимся с ним в разных измерениях (регионах), что требует детального пояснения.

Как известно, трансцендентальное эго Гуссерль рассматривал в контексте соотношения сознания и предмета: cogito (мыслящее себя), cogitatum (мыслимое, осознаваемое) и cogitationes (акты мышления, сознания). В «Картезианских размышлениях» он писал: «Моей трансцендентальной путеводной нитью становится, прежде всего, опытное познание «другого», как он мне дан непосредственно и, глубже, в его ноэмато-онтическом содержании (чисто как коррелят моего cogito...)»5. Другой или опыт Другого дан эго в его собственном опыте и познании.

Персональная реальность человека есть его бытие-для-себя, которое открыто для бытия-длядругих. Бытие-для-себя характеризует способ существования («вместилище») его самости («я сам») и cogito (мыслящее себя), а бытие-для-других наличие в нём другости («я как другой»). При этом понятие «самость» указывает, с моей точки зрения, на универсальную способность человека быть самим собой («быть для себя») в качестве мыслящего существа и его аутентичность (подлинность существования), а другость - на способность быть Другим и с другими.

Бытие-с-другими, как и бытие-для-других, Сартр называет видом онтологической солидарности, необходимой для общей эксплуатации совместного мира 6 . Но, кроме того, оно есть еще и межрегиональное взаимодействие разных персональных реальностей, центральным моментом

\footnotetext{
Гуссерль Э. Картезианские размышления / Пер. с нем. Д.В. Скляднева. СПб.: Наука, 2001. С. 185.

6 Сартр Ж.-П. Бытие и ничто: Опыт феноменологической онтологии. М.: Республика, 2000. С. 269.
} 
которого выступает онтологическая связка «Я Другой». Именно на ней зиждется исходное основание человеческой персональности.

Таким образом, феноменология рассматривается мною как методология (подход) исследования различных форм персональной реальности человека как способов со-бытия и непосредственно взаимодействия Я и Другого, разделяемого далее на сегменты (регионы). Она позволяет исследовать сущее-для-себя (персональную реальность) в аспекте её бытия-с-другими. Я не могу понять себя без Другого и других. Они входят в мою персональную реальность, наполняя её определенным, только мне присущим субъективным смыслом.

\section{Конструирование со-бытия: «Я - Другой» как самонастраивающаяся межрегиональная связь}

Конструирование онтологической связки «Я - Другой» осуществляется путем сборки (и последующей разборки) регионов персональной реальности человека. Понятие «регион» используется мною в значении Э. Гуссерля, т.е. как категории анализа жизненного мира или персональной реальности в моём понимании. Как известно, последний различал формально-логические или материально-онтологические регионы (предметные категории) и субъективные регионы, связанные с переживаниями и представлениями трансцендентального эго (интенциональные объекты) ${ }^{7}$. C предметной данностью имеет дело моё эмпирическое (психологическое) $Я$, а с интенциональными объектами - трансцендентальное эго. При помощи региональной матрицы мы представляем персональную реальность как сферу межрегионального взаимодействия Я и Другого.

Персональная реальность как сфера межрегионального взаимодействия Я и Другого. Совместное бытие Я с другими может происходить независимо от того, присутствует ли рядом Другой или нет. Регион структурирует персональное бытие человека, распределяя потоки его активности, в т.ч. активности по отношению к Другому. Поэтому важно понять то, в каких регионах (сегментах) совместного бытия Я и Другой встречаются и вступают во взаимодействие.

тезис 1. «Я» и «Другой» (или бытие-с-другим) есть персональное выражение и конструирование

Гуссерль Э. Картезианские размышления / Пер. с нем. Д.В. Скляднева. СПб.: Наука, 2001. С. 141-143. межрегионального культурного и солидарного взаимодействия. Иначе говоря, «Я» и Другой находятся в разных регионах или сегментах персональной реальности. Различие между ними носит не только социально-психологический, но и социокультурный характер.

Поясню сказанное выше. Речь здесь идет о преодолении привычного нам географического значения региона и утверждении его особого, социокультурного статуса, который, например, у И. Гофмана имел другие обозначения («фронт», «план» и пр.). Регион характеризует культурно и психологически обособленное пространство персональной реальности/реальностей. В то же время это - определённый фрагмент человеческого сущего, которым занимается наука. Философия же претендует на конструирование всего комплекса регионов персональной реальности, выделяя в качестве центрального звена отношения «Я - Другой».

Следовательно, со-бытие Я и Другого, образующее персональную реальность, её ядро, разделено на регионы, а регион понимается мною не как любое отграниченное пространство персональной реальности одного или нескольких субъектов, отличающихся «внутренним» (духовным) единством, солидарностью или внешним сходством культурных стилей и стандартов жизни. Это - часть жизненного пространства людей, которая предоставляет спектр возможностей и условий для самореализации и понимается несколько уже, чем ареал (в данном случае - сфера распространения и жизнедеятельности живых существ). Регион содержит в себе экзистенциальные и трансцендентные начала.

Вместе с тем регион в моём понимании это дифференцированная совокупность локалов персональной реальности, т.е. местоположений, удобных или комфортных для жизни конкретных человеческих существ как личностей. Регионы персональной реальности образуются из наборов локалов того или иного сообщества (например, те, кого называют знаменитостями, предпочитают работать и отдыхать вместе, держась друг у друга на виду). Но регионы могут объединять людей разного социального положения, хотя их локалы могут не совпадать (например, увлечения, профессии, однокурсники и пр.). Локалы как связи экзистенциального типа у каждого субъекта (индивида или сообщества) свои, а вот регионы могут быть общими. Так, у многих людей имеются излюбленные места отдыха, прогулок, занятия спортом. Но почему-то одни предпочитают ездить на курорты 
и проводить свое свободное время в огромном скопище людей, а другие ищут уединения на даче или где-то еще. Следовательно, локалы ситуативно обусловлены, а регионы имеют социокультурное происхождение.

Круги Я и региональное устройство персональной реальности. О том, что Я имеет круги, распространяющие своё влияние на ближайшее и отдаленное окружение, писал Э. Шпрангер ${ }^{8}$. Кругами он называл смысловые направления или пространства, определяющие в свою очередь основные формы жизни (теоретическую, экономическую, эстетическую, социальную, политическую и религиозную). Они принимают участие в совокупном акте человеческого духа.

Каждому Я, по Шпрангеру, соответствует свой круг влияния и слой предметности. Самый узкий круг образует вожделеющее, телесное Эго или биологическое Я. За ним следуют экономическое, эстетическое, теоретическое, религиозное, коллективное или социальное Я, соответствующие разным формам духа9 ${ }^{9}$ В отличие от Шпрангера я буду рассматривать другие круги Я, которые связаны с конкретными регионами. Я уже обращался к идее множественности Я человека, рассматривая идеальное и реальное Я, актуальное и воображаемое Я, зеркальное и ролевое Я.

Теперь же мне предстоит выделить другие Я, отличные от аутентичного Я - смыслообразующего центра. Это - Я экстернальное (внешне обусловленное), зависящее от окружения, и Я интернальное (внутренне обусловленное), Я включенное, расположенное ближе всего к смыслообразующему центру личности, и Я отстраненное, вытесненное на периферию сферы сознания, актуальное $Я$, находящееся на переднем плане, и Я молчаливое (рефлексирующее), выключенное из активной работы самосознания, невостребованное в данный момент и предпочитающее наблюдать за происходящим вокруг, Я иерархичное, встроенное в систему социальной иерархии и тяготеющее к властной вертикали, и Я автономное, строящее отношения с миром по горизонтали.

Регионы персональной реальности человека подразделяются мною далее по аналогии с идеей фронта (плана бытия) И. Гофмана и в соответствие с

8 См.: Шпрангер Э. Формы жизни: Гуманитарная психология и этика личности / Пер. А.К. Судакова. М.: «Канон+», 2014. C. 88-105.

9 Там же. С. 92-94. разными Я на «передние» и «задние» (актуальное и молчаливое Я), «дальние» и «ближние» (отстраненное и включенное Я), «внутренние» и «внешние» (интернальное и экстернальное Я), «вертикальные» и «горизонтальные» (иерархичное и автономное Я). Во всех типах регионов проявляются как экзистенциальные, так и трансцендентные связи.

Передний и задний регионы - те совокупности местоположений (локалов), которые находятся соответственно у всех на виду, в центре внимания участников межличностного взаимодействия, т.е. на переднем крае, или, напротив, скрыты от посторонних глаз и тяготеют к периферии (задние регионы). В переднем регионе проявляет себя актуальное $Я$, а в заднем - молчаливое $Я$.

Дальние регионы - это пространства, которые мне как субъекту собственной жизни недоступны. Они находятся за пределами моей персональной реальности и зоне влияния отстраненного Я, а ближние - те, которые я лично могу создавать или контролировать как включенное Я. Так, наше присутствие (Dasein) как наиболее близкий нам регион находится рядом с присутствием Другого, входящим в один из дальних регионов. Об этом пишет Хайдеггер: «... Dasein так устроено, оно может быть рядом с другим Dasein, и только поэтому некое другое Dasein, для которого, в свою очередь, дело идет о его бытии, может вступить в экзистентное по своей сути отношение с тем, кто для него - другой» ${ }^{10}$.

«Внешний» и «внутренние» регионы персональной реальности характеризуют соответственно психосоциальные и социокультурные поля, которые задают пространство взаимодействия субъективных и интерсубъективных компонентов личности. К внутренним регионам относятся те свойства или грани жизненного пространства личности, которые отвечают за взаимодействие с непосредственным социальным окружением (фигура и персона), с одной стороны, и определяют её культурный стиль (менталитет) и индивидуальное своеобразие (самость).

«Внутренний» регион - это пространство самореализации и раскрытия потенциал всех Я $^{11}$.

10 Хайдеггер М. Основные проблемы феноменологии / Пер. с нем. А.Г. Чернякова. СПб.: Высшая религиозно-философская школа, 2001. С. 393.

11 См.: Резник Ю.М. Многогранный образ человека: предпосылки построения конфигуративной модели // Вопросы социальной теории: Научный альманах. 2010. T. IV. Человек 
Здесь находится непосредственно моё аутентичное, интернальное «Я» и область экзистенции. А «внешний» регион - сфера взаимодействия экстернального Я с миром, в т.ч. место присутствия Другого или других как суверенных личностей, определяемое, с одной стороны, их положением в обществе (сообществе), а, с другой, интенсивностью их социальной практики (практик) ${ }^{12}$. И в том, и в другом случаях внешний регион представляет собой коридор или поле возможностей личности, которые ей даются либо индивидуально (природой и Богом), либо как представителю социальной группы, сообщества, страны.

Внутренний регион вовлекает в круг общения человека только тех людей, которых он сам выбирает как аутентичное Я. Это относится ко всем без исключения экзистенциально окрашенным Я. Во внешний регион его персональной реальности попадают другие люди, с которыми ему приходится взаимодействовать в общем социальном поле (на работе и местах досуга, в профессиональных сообществах и дружеских компаниях).

Ближний круг образуется вокруг внутреннего региона персональной реальности человека, т.е. его интернального «Я» и «Я» людей, близких ему по духу и находящихся в сфере влияния экстернального Я. Людей, с которыми он связан общей судьбой. Людей, чьи взгляды и убеждения наложили отпечаток на его мировоззренческую позицию. Людей, мнением которых он дорожит превыше всего или с позицией которых считается больше всего.

в поисках идентичности / Под ред. Ю.М. Резника и М.В. Тлостановой. М.: Ассоциация «Междисциплинарное общество социальной теории», 2010. С. 18-62; Резник Ю.М. Человек как предмет комплексного анализа // Методология науки: материалы Всерос. научной школы (Омск, 6-8 сентября 2011 г.) / Отв. ред. В.И. Разумов. Омск: Изд-во ОмГУ, 2011. C. $45-51$.

12 См.: Резник Ю.М. Социальные и культурные практики: интенциональный подход // Культура и культурная политика: Вып. 2: Становление отечественной культурологии: культурология в событиях и лицах / Под общ. ред. О.Н. Астафьевой и В.К. Егорова. М.: МАКС Пресс, 2008. С. 158-168; Резник Ю.М. Социокультурные практики в системе деятельности личности // Постнеклассические практики: определение предметных областей: Материалы межд. семинара / Под общ. ред. О.Н. Астафьевой. М.: МАКС Пресс, 2008. С. 157-185; Резник Ю.М. Основания типологизации социокультурных практик в системе деятельности личности // Постнеклассические практики: опыт концептуализации / Под ред. В.И. Аршинова и О.Н. Астафьевой. СПб.: Изд. дом «Мир», 2012. С. 302-329.
Я полагаю, что для обозначения своего ближнего круга важно учитывать также такие критерии, как взаимодополнительность, совпадение жизненной и гражданской позиций, единство интересов, сходство жизненных обстоятельств, чувство взаимной симпатии и пр.

А теперь вкратце представлю вертикальные и горизонтальные регионы человеческого бытия, где распространяется влияние кругов иерархичного и автономного Я.

Региональные различия Я и разных других. Следует ли из этого, что мой ближний может быть Другим в межрегиональном взаимодействии? Конечно, да, но при определенных условиях. Другой становится ближним, когда попадает в сферу действия моего внутреннего региона. Но он существует свободно и в иных регионах собственной персональной реальности без моего личного участия. И не перестаёт при этом оставаться Другим. Следовательно, моё «Я» сосредоточено во внутреннем, переднем и ближнем регионе. А Я Другого, находясь во внешнем регионе, может (со)участвовать также со мной в переднем, ближнем и дальнем регионах.

Таким образом, передний и задний регионы персональной реальности имеют прямое отношение к организации событий нашей жизни. Как считает Дж. Мид, человеческое существование происходит как последовательность событий, связанных общими условиями или целями. «Мир - это мир событий» ${ }^{13}$. Я существую, а, значит, не только присутствую в мире, но и произвожу события, а также участвую в событиях, организованных другими людьми, близкими мне по каким-либо признакам.

В переднем регионе эти события нами создаются, а в заднем - мы наблюдаем события, организуемые другими людьми и без нашего участия.

Ближний Свой - это также тот, кто находится рядом со мной в силу определенных жизненных обстоятельств. И этим человеком чаще всего оказывается не тот, кто безоговорочно разделяет мои взгляды и убеждения, а человек с другими убеждениями, отстаивающий собственную позицию. Его местонахождение рядом с нами чаще всего не случайно. Мы не всегда выбираем тех, кто нас окружает в ходе жизни. Многие люди попадают в круг нашего общения по факту своего рождения, образования, совместной работы, общности судеб.

13 Мид Дж. Философия настоящего. М.: Изд. Дом Высшей школы экономики, 2014. С. 43. 


\section{Психология и психотехника 8(71) • 2014}

Из этого следует предположение, что ближний как свой Другой в отличие от Чужого - это тот, в событиях которого я могу и хочу участвовать. И, напротив, тот Другой, который участвует в событиях моей жизни и оказывает мне моральную поддержку. И он отличается от Другого, который чужд мне по образу жизни и убеждениям.

Более опасным по сравнению с Чужим выступает Враг. Он отрицает наше существование и стремится разрушить привычный нам образ жизни до основания. Это - непримиримый противник, для которого физическое или моральное уничтожение конкретного человека или группы людей является самоцелью. На этом строится его представление об их персональной реальности. На протяжении своей жизни мы, как и многие люди, сталкиваемся с Врагами, желающими нанести нам какой-либо ущерб. Можно, конечно, успокаивать себя тем, что почти у каждого человека имеются друзья и враги. Но наши враги есть продолжение нас самих. И в том, что они стали врагами имеется доля и нашей вины. Мы в ответе за своё непосредственное окружение. Ведь часто бывает так, что Свой становится вначале Чужим, а в ряде случаев - Врагом. Что-то в нас, видимо, отталкивает его и настраивает против нашего существования, вызывая зависть, агрессию и другие формы острого неприятия.

Совершенно иначе мы взаимодействуем с Иным, от которого нас отделяет не только культура, но и то, что нельзя пересечь (пройти) без определенных усилий или способностей с нашей стороны. Иной - это тот, в событиях которого я, возможно, и хочу, но не всегда могу участвовать по причине отсутствия у меня чего-то большего, чем я есть сам для себя (самость). Возможно, мне не хватает инаковости, способности выходить за пределы себя самого. По-видимому, мне нужно на какое-то время перестать быть обычным человеком и обрести дар общечеловечности, чтобы попасть в мир Иного и обрести чувство сопричастности с ним.

Однако Иной во мне есть ни одно и то же, что Иной как отдельное, не знакомое мне «Я», находящееся от меня на удалении (культурной или психологической дистанции). Этот второй Иной закрыт от меня непрозрачными границами и я не всегда могу к нему достучаться, поскольку он обладает автономией. А вот Иной, находящийся внутри меня, есть продолжение или модификация моего множественного и внутренне дифференцированного «Я», состоящего из конфигурации суб-Я. Иное «Я» отличается от других «Я» во мне стремлением измениться в определенную сторону, быть непохожим на себя или отличным от образа, приписываемого мне некоторыми людьми.

Иной как другое, неизвестное мне лицо находится в дальнем регионе. Нас разделяют с ним культурные, психологические и прочие барьеры. В отличие от чужого Другого он не несёт в себе угрозу моему существованию. Иной же как одно из моих «Я» существует в ближнем регионе и расширяет сферу моего влияния как особый круг. Я могу быть просто Другим, участвуя в событиях конкретного человека, но стать Иным мне гораздо труднее, так как придется менять не только привычный мне образ жизни, но и всю картину мира.

Итак, связка «Я - Другой» существуют в разных или одних и тех же регионах, но в общем социокультурном пространстве. Линия разделения между ними проходит между «внешним» и «внутреннем» регионами. Но они могут различаться также через передний и ближний, передний и задний регионы. Другой как моя вторая половина или полная мне (самости) противоположность является важной частью персональной реальности.

Критерии региональной дифберенциации персональной реальности. Но можно ли отличить «Я» от Другого - Своего, Чужого или Врага, руководствуясь термином «регион»? Для меня ответ состоит в следующем: Свой - это значимый Другой, находящийся по одну сторону со мной, т.е. в переднем регионе персональной реальности, а Чужой отличный от меня Другой, существующий в иной системе культурных и моральных координат, наконец, Враг - Другой, в событиях которого я могу, но не хочу участвовать в силу принципиальных расхождений между нами. Хотя можно сказать и так: поскольку Враг угрожает моему существованию, нанося моральный или физический ущерб, то я избегаю или уклоняюсь от участия в его событиях и стараюсь не допускать его в своё жизненное пространство. А где же тогда проходит линия разделения между этими Другими и как я могу определить в каждый конкретный момент, кто находится перед мной - этот или иной Другой?

Думаю, что ответ на данный вопрос не лежит на поверхности. Можно предположить, конечно, что речь идет о культурном происхождении этих различий между разными другими («Свой - Чужой Враг - Иной»). Но более существенными критериями региональной дифференциации персональной реальности являются возможность/невозможность, желание/нежелание, содействие/противодействие 
участию в событиях или делах конкретного Другого. Возможность, желание и содействие имеют отношение к событиям своего Другого, находящегося со мной в одной системе культурных и социально-психологических координат, невозможность и нежелание, но без активного противодействия - к чужому Другому, который находится в противоположной системе координат. Наконец, невозможность и противодействие характеризует межрегиональное взаимодействие «Я» и Врага.

Таким образом, внутренний и внешний регионы персональности разделяют «Я» и иные формы реальности конкретного человека, в т.ч. реальность Другого. Их различение с точки зрения выделенных мною критериев допускает практически все варианты межрегионального взаимодействия (участие/неучастие, возможность/невозможность, желание/нежелание, содействие/противодействие). Ближний регион персональной реальности предполагает в первую очередь возможность, содействие и желание участия «Я», а дальний невозможность и нежелание «Я» участвовать в событиях Другого, включая активное противодействие в случае с Врагом. В переднем регионе актуальность приобретают возможность и желание/ нежелание участия «Я» в событиях Другого при вероятности содействия/противодействия, а в заднем - невозможность, желание/нежелание и отсутствие содействия/противодействия.

Представим теперь две основные комбинации другости человека, входящей наряду с его самостью в персональную реальность: Другой есть в моём «Я»; мое «Я» есть в Другом. Вместе мы можем составить солидарное и межрегиональное единство где каждый, сохраняя свою самость, обладает другостью - «встречной» или «обоюдной». В известном плане последний вариант является синтезом и высшей формой единства всех модусов человеческой другости, поскольку в ней встречаются эти разные Другие, принадлежащие человеку и не только ему. Они принадлежат также другому человеку как автономной и отличной от него самости.

\section{Деконструкция другости человека: разделение модусов бытия с Другим «я-субъектом» и бытия с Другим «я-объектом»}

Процедуры феноменологической деконструкции персональной реальности человека, центрированной на отношениях Я и Другого, реализуются посредством разделения на два модуса совместного существования: бытие с Другим я-субъектом и бытие с Другим я-объектом.

Я в Другом (бытие с Другим «я-субъектом»). Моё нахождение в Другом, а Другого во мне я именую другостью. В строгом смысле другость - это способность быть Другим, оставаясь при этом самим собой. Другость выражает субстанциальные связи между я-субъектом и я-объектом. По мнению Ж.-П. Сартра, Другой не является для меня исключительно я-объектом и я не всегда выполняю роль субъекта. Поэтому мое бытие-с-другим неполно, если «Я» Другого становится исключительно объектом. Сущностная структура моего бытия характеризует встречу с Другим как я-субъектом, равно как и отношение ко мне как я-субъекту.

Вместе с тем бытие-с-другим, как писал Г. Марсель, означает принадлежность и открытость Другому ${ }^{14}$. Я принадлежу Другому в той мере, в какой он может распоряжаться мной как собой. В то же время я не есть собственность Другого. От меня зависит то, насколько я ему принадлежу. Я же регулирую степень своей открытости Другому.

Тезис 2. Чтобы быть в Другом моему Я необходимо выработать установку открытости и принадлежности Другому, а также научиться строить свои отношения с Другим как субъектом. Отношение к Другому как я-объекту неприемлемо для со-бытия. Бытие-с-другими характеризует меня и Другого как мы-субъект. «...Другой имеет интерес для меня только в той степени, в какой он является другим «Я», Я-объектом для меня и, наоборот, в той степени, в какой он отражает моё «Я», то есть поскольку я есть объектом для него» ${ }^{15}$. Следовательно, мы с Другим в процессе взаимодействия меняемся местами, выступая попеременно то я-объектом, то я-субъектом.

Открытость Другому означает, как подчеркивает Г. Марсель, «выход из сосредоточенности на себе самом и реализация себя прежде всего в самоотдаче и в творчестве во всех его формах» ${ }^{16}$. Открытости соответствует восхищение Другим, его деятельностью как воодушевляющее состояние. Восхищение, как и творчество, предполагает наличие таланта. Поэтому открытость Другому

\footnotetext{
14 См.: Марсель Г. Опыт конкретной философии. М.: Республика, 2004. С. 31-46.

15 Сартр Ж.-П. Бытие и ничто: Опыт феноменологической онтологии. М., 2000. С. 260.

16 Там же. С. 40.
} 
и творческий потенциал человека связаны друг с другом. Неумение оказывать другому моральную и эмоциональную поддержку свидетельствует об отсутствии таланта к восхищению. Напротив, зависть, являясь антиподом восхищения, указывает нам на закрытость человека.

«Я» в Другом реализует себя через заботу или иное великодушное начинание. Моё присутствие в Другом характеризует участие в его бытии, заботу о нём. «Другой как другого существует для меня лишь постольку, поскольку я открыт по отношению к нему, но я открыт в той мере, в какой я больше не черчу своего рода круг, в рамки которого я загоняю другого или, скорее, его идею» ${ }^{17}$.

Иначе говоря, можно по-разному проявлять свою другость. Другой во мне находится рядом, в конкретной ситуации взаимодействия с миром, а «Я» в Другом пребывает в там-бытии, на неопределенной дистанции и не всегда в будущем, как мне бы это хотелось. Я не могу попасть в будущее, минуя настоящее, но я могу его актуализировать посредством Другого. Иначе говоря, попасть в него я могу через Другого, владеющего иным, пока еще недоступным мне опытом.

Другой во мне (бытие с Другим «я-объектом»). Рассмотрим еще один аспект другости: Другой во мне самом. Другой во мне характеризуется, по Сартру, как тот, кто смотрит на меня ${ }^{18}$. Он знает и помнит обо мне. Его взгляд на меня входит в моё присутствие и направляет мою жизнь. Я есть то, что я есть, поскольку являюсь объектом для сознания Другого.

Tезис 3. Другой во мне находится в моём же собственном присутствии. В отношении меня Другой выступает как я-субъект, тогда как на мне лежит ответственность за бытие-сдругими и я добровольно принимаю на себя позицию я-объекта.

Другой во мне оставляет следы своего присутствия. Но моё присутствие включает присутствие Другого не полностью, а избирательно. Приведу расшифровку выражения: «Я там, где меня нет (в данный момент или вообще)». Речь идет о вотбытии или присутствии, в котором есть место моему Другому. Чтобы глубже понять вот-бытие как бытие в настоящем, в т.ч. бытие-с-другими, следует обратиться к философии настоящего Дж. Мида. На-

\footnotetext{
17 Там же. С. 58.

18 Сартр Ж.-П. Бытие и ничто: Опыт феноменологической онтологии. М., 2000. С. 280.
}

стоящее для него есть локус реальности, еще не завершившей своё существование для меня.

У каждого человека имеется свой ритм времени присутствия, трудно согласуемый со среднестатистическим. Его текущая жизненная динамика отличается от динамических моделей поведения других людей. Парадокс ситуации заключается в том, что мы переживаем разные субъективные времена в своем присутствии, хотя живём в общем (согласованном или скоординированном) времени, т.е. в со-присутствии. Так нам проще и удобнее соотносится друг с другом. И для этого каждому из нас требуется настроиться на волну времени Другого, чтобы пробудить интерес к нему.

Но пробудить интерес к Другому вообще и Другого в себе - это не значит расстаться со своей самостью, перестать быть самим собой или стать одним из внешних Других. Актуализация различных образов Другого есть искусство жизни между мирами. Я не могу жить одновременно в разных мирах и тем самым иметь много самостей, но я могу быть множественным Другим. Самость у человека, как правило, одна, а Других в нём много. И я могу увидеть мир глазами Другого (или многих других), поступая так, как будто я и есть тот самый Другой, которого на самом деле создал силой собственного воображения. Быть Другим не так уж сложно, если вжиться в его образ, труднее всего сохранить и не расплескать самого себя.

Выводы. 1. В качестве подхода к исследованию проблемы «Я - Другой» автор использует феноменологию, которая располагает тремя методами: редукция, конструкция и деконструкция.

2. Благодаря первому методу (редукция) осуществляется «возведение» (восхождение) сущего к способам бытию - бытию-для-себя и бытию-длядругих или с другими, составляющие содержание персональной реальности. Бытие-с-другими есть особый вид бытия-в-мире. Другой во мне также необходим, как и Я в Другом. Вместе они составляют бытие-с-другими, которое возможно как со-бытие и в качестве мы-субъекта. Здесь намечается переход экстерриториального к межрегиональному взаимодействию, протекающему на надличностном уровне.

3. Далее производиться процедура конструирования персональной реальности с использованием региональной матрицы человеческого бытия, разделяющей его на смысловые пространства (поля) - регионы. Внутри- и межрегиональные различия Я и Другого определяются в значительной мере воздействием кругов Я человека. 
4. Наконец, проблема «Я - Другой» как системообразующий центра персональной реальности подлежит деконструкции. Я как Другой - это обратная, зазеркальная сторона бытия-с-другими.
Она начинается со встречи с собой в качестве Другого. Затем осуществляется аналитическая дифференциация модусов бытия-с-Другим - бытия «я-субъектом» и бытия «я-объектом».

\section{Список литературы:}

1. Гуссерль Э. Картезианские размышления / Пер. с нем. Д.В. Скляднева. СПб.: Наука, 2001. 316 с.

2. Марсель Г. Опыт конкретной философии. М.: Республика, 2004. С. 31-46.

3. Мид Дж. Философия настоящего. М.: Изд. Дом Высшей школы экономики, 2014. 272 с.

4. Резник Ю.М. Многогранный образ человека: предпосылки построения кон-фигуративной модели // Вопросы социальной теории: Научный альманах. 2010. T. IV. Человек в поисках идентичности / Под ред. Ю.М. Резника и М.В. Тлостановой. М.: Ассоциация «Междисциплинарное общество социальной теории», 2010. С. 18-62.

5. Резник Ю.М. Основания типологизации социокультурных практик в системе деятельности личности // Постнеклассические практики: опыт концептуализации / Под ред. В.И. Аршинова и О.Н. Астафьевой. СПб.: Изд. дом «Мир», 2012. С. 302-329.

6. Резник Ю.М. Социальные и культурные практики: интенциональный подход // Культура и культурная политика: Вып. 2: Становление отечественной культурологии: культурология в событиях и лицах / Под общ. ред. О.Н. Астафьевой и В.К. Егорова. М.: МАКС Пресс, 2008. С. 158-168.

7. Резник Ю.М. Социокультурные практики в системе деятельности личности // Постнеклассические практики: определение предметных областей: Материалы межд. семинара / Под общ. ред. О.Н. Астафьевой. М.: МАКС Пресс, 2008. С. 157-185.

8. Резник Ю.М. Человек как предмет комплексного анализа // Методология науки: материалы Всерос. научной школы (Омск, 6-8 сентября 2011 г.) / Отв. ред. В.И. Разумов. Омск: Изд-во ОмГУ, 2011. С. 45-51.

9. Сартр Ж.-П. Бытие и ничто: Опыт феноменологической онтологии. М., 2000.

10. Хайдеггер М. Основные проблемы феноменологии / Пер. с нем. А.Г. Чернякова. СПб.: Высшая религиозно-философская школа, 2001. 446 с.

11. Ясперс К. Разум и экзистенция. М.: Канон + РООИ «Реабилитация», 2014. 336 с.

\section{References (transliteration):}

1. Gusserl' E. Kartezianskie razmyshleniya / Per. s nem. D.V. Sklyadneva. SPb.: Nauka, 2001. 316 s.

2. $\quad$ Marsel' G. Opyt konkretnoi filosofii. M.: Respublika, 2004. S. 31-46.

3. Mid Dzh. Filosofiya nastoyashchego. M.: Izd. dom Vysshei shkoly ekonomiki, 2014. $272 \mathrm{~s}$.

4. Reznik Yu.M. Mnogogrannyi obraz cheloveka: predposylki postroeniya kon-figurativnoi modeli // Voprosy sotsial'noi teorii: Nauchnyi al'manakh. 2010. T. IV. Chelovek v poiskakh identichnosti / Pod red. Yu.M. Reznika i M.V. Tlostanovoi. M.: Assotsiatsiya «Mezhdistsiplinarnoe obshchestvo sotsial'noi teorii», 2010. S. 18-62.

5. Reznik Yu.M. Osnovaniya tipologizatsii sotsiokul'turnykh praktik v sisteme deyatel'nosti lichnosti // Postneklassicheskie praktiki: opyt kontseptualizatsii / Pod red. V.I. Arshinova i O.N. Astaf'evoi. SPb.: Izd. dom «Mir», 2012. S. 302-329.

6. Reznik Yu.M. Sotsial'nye i kul'turnye praktiki: intentsional'nyi podkhod // Kul'tura i kul'turnaya politika: Vyp. 2: Stanovlenie otechestvennoi kul'turologii: kul'turologiya v sobytiyakh i litsakh / Pod obshch. red. O.N. Astaf'evoi i V.K. Egorova. M.: MAKS Press, 2008. S. 158-168.

7. Reznik Yu.M. Sotsiokul'turnye praktiki v sisteme deyatel'nosti lichnosti // Postneklassicheskie praktiki: opredelenie predmetnykh oblastei: Materialy mezhd. seminara / Pod obshch. red. O.N. Astaf'evoi. M.: MAKS Press, 2008. S. 157-185.

8. Reznik Yu.M. Chelovek kak predmet kompleksnogo analiza // Metodologiya nauki: materialy Vseros. nauchnoi shkoly (Omsk, 6-8 sentyabrya 2011 g.) / Otv. red. V.I. Razumov. Omsk: Izd-vo OmGU, 2011. S. 45-51.

9. Sartr Zh.-P. Bytie i nichto: Opyt fenomenologicheskoi ontologii. M., 2000.

10. Khaidegger M. Osnovnye problemy fenomenologii / Per. s nem. A.G. Chernyakova. SPb.: Vysshaya religioznofilosofskaya shkola, 2001.446 s.

11. Yaspers K. Razum i ekzistentsiya. M.: Kanon + ROOI «Reabilitatsiya», 2014. 336 s. 